\title{
EDUCAÇÃO PÚBLICA, GRATUITA E OBRIGATÓRIA: notas controversas sobre vagas em creche
}

\author{
José Claudinei Lombardi ${ }^{1}$
}

\section{RESUMO}

Este texto apresenta alguns apontamentos sobre o oferecimento de educação infantil para os filhos dos trabalhadores, cujo direito é certo, porém não está claro de quem é a obrigação. As profundas transformações econômicas, sociais, políticas ou culturais que ocorrem no mundo contemporâneo, que atingem a formação social brasileira, não são meras transformações superficiais, e nem simples mudanças conjunturais. Com relação à educação, apesar das rápidas mudanças que ocorreram ao longo do século XX e nos anos iniciais deste novo século, ainda se busca a universalização quantitativa e qualitativa da educação básica. Na cidade de Limeira, a universalização do ensino fundamental em termos quantitativos já havia se cumprido no século XX, mas com a persistência dos problemas qualitativos. $\mathrm{O}$ ensino médio ainda não atende à totalidade dessa faixa populacional. Porém, o maior gargalo em Limeira localiza-se na educação infantil, que ainda é necessário ampliar quantitativamente o atendimento, de forma a atender a Constituição Federal, que é clara ao determinar o dever de assistência gratuita aos filhos e dependentes de empregados, até que aqueles cheguem à idade de cinco anos. A respeito de quem é a obrigação em dar assistência gratuita aos filhos dos trabalhadores do nascimento até os cinco anos de idade, a Constituição Federal não deixa dúvidas de que aos patrões cabe essa obrigatoriedade e, por isso, nem há como deixar de reconhecer como direito líquido e certo a assistência e educação infantil para os filhos dos trabalhadores do nascimento até os cinco anos de idade.

Palavras-chave: Educação Pública; Educação Infantil; Cidade de Limeira

\section{PUBLIC EDUCATION, FREE AND COMPULSORY: controversial notes about vacancy in Childcare center}

\begin{abstract}
This paper presents some notes about offering early education for the children of workers whose right is right, but it is not clear where the obligation. The profound economic, social, political and cultural transformations occurring in the contemporary world, hitting the Brazilian social formation, are not mere superficial changes, and not simply a change in circumstances. With regard to education, despite the rapid changes that have occurred throughout the twentieth century and the early years of this new century, still seeking the quantitative and qualitative universal basic education. In the city of Limeira, the universalization of elementary education in quantitative terms had been fulfilled in the twentieth century, but with the persistence of the qualitative problems . The high school still does not meet the entire range of this population. However, the biggest bottleneck in Limeira located in early childhood education, it is still necessary to expand quantitatively care, to meet the Federal Constitution, which is clear in determining the duty of care is free for children and dependents of employees until those reaching the age of five years. About whom is obliged to give free care to the children of workers from birth to age of five years, the Constitution leaves no doubt that the bosses fits that requirement and therefore there is not as fail to recognize how law net and the right child care and education for workers' children from birth to age of five years.
\end{abstract}

Keywords: Public Education ; Early Childhood Education ; city of Limeira 


\section{Transformações econômicas, sociais e educacionais}

Tenho escrito e falado sobre as profundas transformações que ocorrem no mundo contemporâneo, e que também atingem a formação social brasileira. Não são meras transformações superficiais, e nem simples mudanças conjunturais que, em seu sentido etimológico, somente dizem respeito a determinados acontecimentos ou circunstâncias que expressam um dado momento - econômico, social, político ou cultural. Como pesquisador no campo da filosofia e da história da educação tenho argumentado e buscado demonstrar que são profundas transformações estruturais, características da transição de um padrão societário e civilizatório para outro.

Sem compreensão clara dessas transformações, tornou-se lugar comum - não só entre cidadãos, mas também entre educadores, juristas e intelectuais de diversos campos o entendimento de que compete ao Estado (em seus diferentes níveis, nacional, estaduais e municipais) o atendimento à educação infantil e fundamental, pública e gratuita, mas também obrigatória, a todas as crianças, independentemente da idade e do nível educacional. Mas o interessante a observar é que essa orientação é válida somente para desonerar a iniciativa privada (leia-se, o capital); também é usual para que, em tempos de crise, recursos públicos salvem a "falência" privada, em todos os setores, notadamente do sistema financeiro; entretanto, o contrário jamais é verdadeiro.

Para que não fique dúvida quando ao que defendo, não canso de registrar meu entendimento e compromisso, como educador, de que numa sociedade com classes diferenciadas, como a nossa, a educação deve ser prioritariamente pública, gratuita, laica e competente. Essa é a única garantia para que a massa trabalhadora receba uma formação de qualidade, condição para se viver numa sociedade letrada, e tenha condições de exercício crítico que possibilite engajamento político com vistas a alavancar sua luta emancipatória. Entretanto, por um lado, é longa a história da luta pela universalização da educação, bem como por uma educação de qualidade; por outro, é preciso estar atento para as profundas contradições que marcam as transformações do mundo contemporâneo e que também afetam a educação em nosso país e, de modo particular, do município de Limeira.

Acompanhando as transformações econômicas, sociais e políticas da formação social brasileira, também são aceleradas as mudanças na dinâmica demográfica, com a redução da natalidade e da população jovem e o envelhecimento da população, com a ampliação da chamada "terceira idade". Essa mudança pode ser rapidamente observada pelos dados demográficos, bem como pela visualização da mudança na pirâmide populacional do Brasil ${ }^{2}$ - e, particularmente, de modo ainda mais acentuado, para Limeira ${ }^{3}$ - decorrência de seu processo histórico marcado pela urbanização e industrialização, notadamente a partir da década de 1980.

Que conclusões tirar dessas mudanças da dinâmica populacional? 1) que a taxa de crescimento do município vem caindo paulatinamente; 2) que está havendo taxa de crescimento negativa para a população de 0 a 3 anos - e que demanda vaga em creche (entre 2000 a 2010 foi de -18\%; que continuará caindo nas previsões para as décadas futuras); 3) que também está havendo crescimento negativo da população de 4 a 6 anos (no período de 2000 a 2010 foi de $-15,1 \%$ ); e 4) também crescimento negativo da população de 7 a 10 anos (idem, -10,2\%). O crescimento positivo da população começa a se verificar para a população com a partir dos 25 anos de idade, com aumento crescente da população com mais de 65 anos de idade. 


\section{Educação em Limeira: universalização do ensino fundamental, gargalo na educação infantil}

Com relação à educação, os dados disponíveis também indicam que rápidas mudanças ocorreram ao longo do século XX e nestes anos iniciais deste novo século. Em nível nacional, ainda se busca a universalização quantitativa da educação básica, com inicio de programas centrados na busca por melhoria da qualidade - como o Pacto Nacional pela Alfabetização na Idade Certa e outros programas que trilham, entretanto, caminhos recentes em busca de melhores indicadores de aprendizagem. Com relação à Limeira, ainda no século XX a universalização quantitativa do ensino fundamental, tanto de $1^{\mathrm{a}}$. a $4^{\mathrm{a}}$. quanto de $5^{\mathrm{a}}$. a $8^{\mathrm{a}}$. séries já havia se cumprido. Em termos quantitativos, não há falta de vagas no ensino fundamental; mas persistem os problemas qualitativos, com queda nos indicadores de qualidade, como o IDEB e o IDESP - mas esse é um assunto que exigirá maior atenção e, por isso, assunto para uma próxima matéria. $\mathrm{O}$ gargalo no ensino médio ainda se mantém, nível de ensino que ainda não atende à totalidade dessa faixa populacional em idade escolar.

O maior gargalo em Limeira, porém, localiza-se na educação infantil. Segundo o Censo de 2000, haviam 16.525 crianças de 0 a 3 anos; dessas somente 1.354 crianças $(8,19 \%)$ eram atendidas em creche, sendo 1.181 em unidades educacionais municipais e 173 particulares. Em 2010 houve a redução de $-18 \%$ de crianças de 0 a 3 anos, com 13.633 bebês nessa faixa etária; houve redução absoluta de crianças, mas houve um grande aumento de vagas em creche (de 222,67\%) que passaram para 4.369 crianças atendidas (32\% de crianças atendidas), sendo 3.089 em creches municipais e 1.280 em particulares. Além do crescimento de vagas em creches municipais, o destaque fica por conta da introdução do programa Bolsa Creche, financiado com recursos públicos, e que bancou a ampliação de instituições privadas no setor (eram 796 crianças bancadas pelo bolsa creche, e 484 matriculas particulares). Os dados estimativos da população para 2012 indicam estabilização na quantidade de crianças de 0 a 3 anos, podendo-se registrar os mesmos 13.633 bebês; mas é preciso destacar que houve explosivo aumento de vagas em apenas 2 anos, quando foram disponibilizadas 5.949 vagas em creche (passando-se a atender a 43,6\% mais crianças em relação a 2010). As vagas em creches públicas passaram para 3.936 vagas (crescimento de 27,4\%) e as particulares ampliaram para 2.013 (um crescimento de 57,3\% em apenas dois anos), reforçando que, aceleradamente, recursos públicos financiaram o crescimento das vagas em creches privadas.

Surpreendente é que não só continuou a carência em atendimento pré-escolar, como o fosso aumentou no mesmo decênio. A população da faixa etária de 4 a 6 anos de idade era de 12.077 crianças em 2000 e, tendo redução de $-15,1 \%$ passou para 10.248 em 2010. A estimativa para 2012 também é de estabilização - com indicação de 10.236 crianças nessa faixa etária. Para o atendimento pré-escolar os dados disponíveis indicam crescimento do atendimento escolar desse nível de ensino, passando-se de 1.884 crianças atendidas em 1980, para 7.135 em 1990, um crescimento de 278,7\% em apenas uma década, contra um aumento de $29,5 \%$ dessa faixa etária). As instituições particulares duplicaram o atendimento nessa década, de 654 para 1305 alunos, mas o espetacular crescimento deu-se por conta da forte ampliação de vagas na rede pública que passou de 1.098 em 1980 para 5.678 alunos em 1990 - um crescimento de 417\% de vagas em préescola municipal. Em 2000 o crescimento arrefeceu, registrando "apenas" 22,8\% de crescimento, com 8.763 vagas em pré-escola - crescimento ficou por conta de 
investimento público que aumentou para 7.644 vagas, um aumento de $35 \%$ em relação a 1990; redução de $-14 \%$ das vagas em pré-escolas privadas, que atenderam a 1.119 alunos.

O mais interessante é o que ocorreu na década seguinte, parcialmente explicando o aumento das vagas em creches na década entre 2000 a 2010. Queda para $5.364(-38,8 \%)$ no total de vagas na pré-escola; sendo 4.677 (-38,8\%) em instituições municipais e 687 ($38,6 \%$ ) em escolas particulares. É preciso pesquisar o assunto com mais detalhe, mas os dados indicam que houve transferência de vagas de atendimento da demanda por creche. Em 2012 os dados indicam crescimento de 12\% na oferta de vagas nesse nível, indo para 6.014 vagas no total; dessas $5.106(9,17 \%)$ em pré-escolas municipais e 908 32,2\%) em escolinhas privadas.

É preciso elucidar - através de pesquisas mais profundas - o vertiginoso crescimento do atendimento à educação básica, notadamente identificando as classes e frações de classe que esse crescimento beneficia. Tenho como hipótese de trabalho que essa universalização atendeu majoritariamente aos filhos dos trabalhadores e que, por isso, houve reforço negativo da dualidade que marca a história da educação brasileira. Se originalmente a dualidade pressupunha escolarização diferente para classes diferentes e antagônicas (educação intelectual para a burguesia; qualificação profissional para os trabalhadores), a universalização ocorreu sem atendimento a pré-condições para o pleno funcionamento das escolas, em quaisquer de seus níveis. Não me refiro apenas a prédios e instalações escolares, a equipamentos voltados ao ensino, e aos livros e manuais didáticos, mas principalmente a uma acelerada ampliação de uma educação precarizada, que precisou contratar trabalhadores da educação precariamente formados e em condições precarizadas de trabalho. Os filhos da elite continuaram a receber formação diferenciada e a educação estatal precarizada destinou-se, fundamentalmente, ao atendimento dos filhos das classes trabalhadoras.

Por isso, não há dúvida que o processo de universalização do ensino fundamental ainda está a exigir QUALIDADE, uma vez que o domínio dos conteúdos educacionais ainda estão muito aquém do necessário. Mas essa é uma discussão que exige aprofundamento, coleta de dados e uma análise mais minuciosa.

\section{Educação Infantil: entendendo a legislação}

Pelo exposto anteriormente, não há dúvida de que ainda é necessário ampliar quantitativamente o atendimento na educação infantil, de forma a atender a legislação educacional. Inicialmente, deve-se atentar para os termos do art. 227 da Constituição Federal, que estabelece que a corresponsabilidade da família, da sociedade e do Estado em assegurar à criança seus direitos:

\footnotetext{
Art. 227. É dever da família, da sociedade e do Estado assegurar à criança, ao adolescente e ao jovem, com absoluta prioridade, o direito à vida, à saúde, à alimentação, à educação, ao lazer, à profissionalização, à cultura, à dignidade, ao respeito, à liberdade e à convivência familiar e comunitária, além de colocá-los a salvo de toda forma de negligência, discriminação, exploração, violência, crueldade e opressão. (Redação dada Pela Emenda Constitucional no 65, de 2010).
} 
Antes, o Art. 208 da lei magna já estabeleceu o que é garantido à criança, claramente diferenciando os direitos gerais e universais, daquilo que o Estado deve garantir de modo gratuito e OBRIGATÓRIO, dos 4 aos 17 anos de idade, como segue:

Art. 208. O dever do Estado com a educação será efetivado mediante a garantia de:

I - ensino fundamental, obrigatório e gratuito, inclusive para os que a ele não tiveram acesso na idade própria;

II - progressiva extensão da obrigatoriedade e gratuidade ao ensino médio;

I - ensino fundamental, obrigatório e gratuito, assegurada, inclusive, sua oferta gratuita para todos os que a ele não tiveram acesso na idade própria; (Redação dada pela Emenda Constitucional nº 14, de 1996)

I - educação básica obrigatória e gratuita dos 4 (quatro) aos 17 (dezessete) anos de idade, assegurada inclusive sua oferta gratuita para todos os que a ela não tiveram acesso na idade própria; (Redação dada pela Emenda Constitucional $n^{\circ}$ 59, de 2009) (Vide Emenda Constitucional $\mathrm{n}^{\mathrm{o}}$ 59, de 2009)

II - progressiva universalização do ensino médio gratuito; (Redação dada pela Emenda Constitucional n ${ }^{\circ} 14$, de 1996)

III - atendimento educacional especializado aos portadores de deficiência, preferencialmente na rede regular de ensino;

IV - atendimento em creche e pré-escola às crianças de zero a seis anos de idade;

IV - educação infantil, em creche e pré-escola, às crianças até 5 (cinco) anos de idade; (Redação dada pela Emenda Constitucional n ${ }^{\circ} 53$, de 2006)

$\cdots$

VII - atendimento ao educando, no ensino fundamental, através de programas suplementares de material didático-escolar, transporte, alimentação e assistência à saúde.

$\S 1^{\circ}$ - O acesso ao ensino obrigatório e gratuito é direito público subjetivo.

$\S 2^{\circ}$ - O não-oferecimento do ensino obrigatório pelo Poder Público, ou sua oferta irregular, importa responsabilidade da autoridade competente.

$\S 3^{\circ}$ - Compete ao Poder Público recensear os educandos no ensino fundamental, fazer-lhes a chamada e zelar, junto aos pais ou responsáveis, pela frequência à escola.

Não há dúvida que ao Estado cabe prover pública e gratuitamente o atendimento ao ensino fundamental como fica devidamente explicitado no $\S 1^{\circ}$, da alínea VII do Artigo 208 da CF, que coloca este como um direito público subjetivo - e que, portanto, lato sensu é um "direito do sujeito". Recentemente houve mudança quanto a obrigatoriedade da educação infantil. Inicialmente, atendendo disposto na Constituição Federal de 1988, em 26 de dezembro de 1996, foi editada a Lei $n^{\circ}$ 9.394/96 - Lei de Diretrizes e Bases da Educação (LDB), houve regulamentação de vários aspectos e questões dos processos 
formativos e que se desenvolvem na vida familiar, na convivência humana, no trabalho, nas instituições de ensino e pesquisa, nos movimentos sociais e organizações da sociedade civil e nas manifestações culturais. A OBRIGATORIEDADE de educação infantil pública e gratuita ficou definido também nessa lei a partir dos 5 (cinco) anos de idade, MAS, o caráter público e OBRIGATÓRIO da educação infantil foi mudado por alterações da Lei de Diretrizes e Bases da Educação Nacional, através da LEI No 12.796, de 4 de abril de 2013, que entre outras mudanças, no Art. $4^{\circ}$. Inciso I, reduz a OBRIGATORIEDADE de matrícula em escolas de Educação Infantil para crianças a partir de 4 anos de idade. Hoje a base legal é que segue:

Art. $4^{\circ} \mathrm{O}$ dever do Estado com educação escolar pública será efetivado mediante a garantia de:

I - educação básica obrigatória e gratuita dos 4 (quatro) aos 17 (dezessete) anos de idade, organizada da seguinte forma: (Redação dada pela Lei ${ }^{\circ} 12.796$, de 2013)

a) pré-escola; (Incluído pela Lei no 12.796, de 2013)

b) ensino fundamental; (Incluído pela Lei $\mathrm{n}^{\circ} 12.796$, de 2013)

c) ensino médio; (Incluído pela Lei n ${ }^{\circ} 12.796$, de 2013)

II - educação infantil gratuita às crianças de até 5 (cinco) anos de idade; (Redação dada pela Lei $n^{\circ} 12.796$, de 2013)

$\S 2^{\circ}$ Em todas as esferas administrativas, o Poder Público assegurará em primeiro lugar o acesso ao ensino obrigatório, nos termos deste artigo, contemplando em seguida os demais níveis e modalidades de ensino, conforme as prioridades constitucionais e legais.

A legislação educacional, que é certamente complexa, não deixa dúvidas que a OBRIGATORIEDADE e GRATUIDADE da educação escolar é para crianças, adolescentes e jovens entre os 04 (quatro) e os 17 (dezessete) anos de idade, sendo que a idade mínima limite deverá ser obrigatoriamente cumprida a partir de 2016. A obrigatoriedade engloba a educação pré-escolar, o ensino fundamental e o ensino médio.

\section{Educação Infantil dos filhos dos trabalhadores: entendendo a legislação}

No caso dos FILHOS DE TRABALHADORES, urbanos ou rurais, a garantia legal é, ao mesmo tempo, mais complexa e ampliada, não eximindo as empresas de suas responsabilidades. A Constituição Federal é clara ao determinar o dever de assistência gratuita aos filhos e dependentes de empregados, até que aqueles cheguem à idade de 05 anos, como segue:

Art. $7^{\mathbf{0}}$ São direitos dos trabalhadores urbanos e rurais, além de outros que visem à melhoria de sua condição social:

...

XXV - assistência gratuita aos filhos e dependentes desde o nascimento até 5 (cinco) anos de idade em creches e pré-escolas; (Redação dada pela Emenda Constitucional $n^{\circ} 53$, de 2006)

Não se trata de legislação recém-produzida, no calor do processo de redemocratização do Brasil. A legislação fabril inglesa, por exemplo, na qual paralelamente ao ingresso da força de trabalho da mulher foi se construindo a obrigatoriedade com o cuidado dos filhos das mães trabalhadoras, foi sendo elaborada ao 
longo do século XIX. No Brasil, o reconhecimento do direito dos trabalhadores terem seus filhos em local apropriado (creche) foi conquistado somente com o Decreto-Lei $\mathrm{n}^{\circ}$ 5.452, de 1 de maio de 1943, sancionado pelo então presidente Getúlio Vargas, unificando toda legislação trabalhista existente no Brasil. Na Consolidação das Leis do Trabalho estabeleceu-se que, nos termos do $\S 1^{\circ}$ do art. 389 da CLT, os estabelecimentos em que trabalhem, pelo menos, 30 mulheres com mais de 16 anos de idade devem possuir local apropriado para guarda, sob vigilância e assistência, dos filhos no período de amamentação. Essa mesma legislação traça 3 (três) opções às empresas que possuam em seu quadro funcional pelo menos 30 (trinta) mulheres com mais de 16 (dezesseis) anos:

\section{a) Creche Própria:}

"Art. 389. (...)

$\S 1^{\circ}$ Os estabelecimentos em que trabalharem pelo menos 30 (trinta) mulheres com mais de 16 (dezesseis) anos de idade terão local apropriado onde seja permitido às empregadas guardar sob vigilância e assistência os seus filhos no período da amamentação."

\section{b) Convênio com Creche Externa:}

""Art. 389. (...)

$\S 2^{\circ}$. A exigência do $\S 1^{\circ}$ poderá ser suprida por meio de creches distritais mantidas, diretamente ou mediante convênios, com outras entidades públicas ou privadas, pelas próprias empresas, em regime comunitário, ou a cargo do SESI, do SESC, da LBA ou de entidades sindicais." e

"Art. 397 O SESI, o SESC, a LBA e outras entidades públicas destinadas à assistência à infância manterão ou subvencionarão, de acordo com suas possibilidades financeiras, escolas maternais e jardins de infância, distribuídos nas zonas de maior densidade de trabalhadores, destinados especialmente aos filhos das mulheres empregadas."

"Art. 400. Os locais destinados à guarda dos filhos das operárias durante o período da amamentação deverão possuir, no mínimo, um berçário, uma saleta de amamentação, uma cozinha dietética e uma instalação sanitária."

\section{c) Reembolso Creche:}

assim determina a Portaria 3.296, art. $1^{o}$, II:

"II - O benefício deverá ser concedido a toda empregada-mãe, independente do número de mulheres do estabelecimento, e sem prejuizo do cumprimento dos demais preceitos de proteção à maternidade"

Súmula 310 STJ: "O auxílio-creche não integra o salário de contribuição".

Art. 444 da CLT: "As relações contratuais de trabalho podem ser objeto de livre estipulação das partes interessadas em tudo quanto não contravenha às disposições de proteção ao trabalho, aos contratos coletivos que lhes sejam aplicáveis e às decisões das autoridades competentes.

A creche de que trata a lei teve suas características definidas pela Portaria DNSHT no 1/69, que estabeleceu que o local para guarda dos filhos dos empregados deve observar os seguintes requisitos:

a) berçário com área mínima de $3 \mathrm{~m}^{2}$ por criança, devendo haver, entre os berços e entre estes e as paredes, no mínimo, a distância de 0,50 $\mathrm{cm}$; 
b) o número de leitos no berçário obedecerá à proporção de um leito para cada grupo de 30 empregadas entre 16 e 40 anos de idade;

c) saleta provida de cadeiras ou bancos-encosto para amamentação, em adequadas condições de higiene e conforto;

d) cozinha dietética para o preparo de mamadeiras ou suplementos dietéticos para a criança ou para as mães;

e) revestimento no piso e paredes de material lavável e impermeável;

f) instalações sanitárias para uso das mães e do pessoal da creche.

No caso de Bolsa Creche, ou similar, como afirmado, o assunto foi regulamentado pela Portaria $n^{\circ}$ 3296/86, de 03/09/86, alterada pela Portaria MTb $n^{\circ}$ 670/97. Em substituição à obrigatoriedade de se manter local apropriado onde seja permitida a empregada-mãe guardar seus filhos ou creche, a empresa poderá adotar o sistema de reembolso-creche, desde que obedecidos os seguintes requisitos:

a) o reembolso-creche deve cobrir, integralmente, as despesas efetuadas com o pagamento da creche de livre escolha da empregada-mãe ou outra modalidade de prestação de serviço desta natureza, pelo menos até os seis meses de idade da criança, nas condições, prazos e valor estipulados em acordo ou Convenção Coletiva;

b) conceder o benefício a toda empregada-mãe, independentemente do número de mulheres do estabelecimento, e sem prejuízo do cumprimento dos demais preceitos de proteção à maternidade;

c) dar ciência às empregadas da existência do sistema e dos procedimentos necessários para utilização do benefício, com afixação de avisos em locais visíveis e de fácil acesso aos empregados;

d) efetuar o reembolso-creche até o $3^{\circ}$ dia útil da entrega do comprovante das despesas efetuadas, pela empregada-mãe, com a mensalidade da creche.

A implantação do benefício do reembolso-creche depende de prévia estipulação em acordo ou Convenção Coletiva de trabalho, exceto aos órgãos públicos e às instituições paraestatais referidas no art. 397 da CLT. Ademais, a adoção de qualquer sistema alternativo à exigência prevista na CLT, deve ser comunicada ao órgão local do Ministério do Trabalho e Emprego (MTE), ao qual compete analisar se eles estão em consonância com a legislação vigente. Deve-se destacar que o art. $214, \S 9^{\circ}$, inciso XXIII, do Regulamento da Previdência Social (RPS), aprovado pelo Decreto $n^{\circ} 3.048 / 99$, dispõe que não integra o salário-de-contribuição, exclusivamente, o reembolso-creche pago em conformidade com a legislação trabalhista, observado o limite máximo de cinco anos de idade da criança, quando devidamente comprovadas as despesas. Ainda, o art.15, § $6^{\circ}$, da Lei ${ }^{\circ} 8036 / 90$, estabelece que não se incluem na remuneração, para fins de incidência do FGTS, as parcelas elencadas no $\S 9^{\circ}$, "s", do art. 28, da Lei n ${ }^{\circ} 8.212 / 91$. "Art. 28, $\S 9^{\circ}$ - não integram o salário-de-contribuição para os fins desta lei, exclusivamente: o reembolsocreche pago em conformidade com a legislação trabalhista, observado o limite máximo de 6 anos de idade, quando devidamente comprovadas as despesas realizadas."

\section{Concluindo - Educação infantil para os filhos dos trabalhadores: direito líquido e certo, mas obrigação de quem?}

Como se sabe pela historiografia da educação infantil, o atendimento institucional das crianças compreendendo o período antecedente à escolarização formal tem suas 
origens no século XIX e visava, fundamentalmente, ao cuidado físico e moral requeridos à formação do indivíduo em seus anos iniciais de vida. Essa institucionalização ainda está ocorrendo em âmbito internacional, do século XIX até a atualidade, decorrência direta da expansão da industrialização e do setor de serviços, da intensificação da urbanização, com a reorganização das comunidades e estruturas de organização familiar, com a incorporação do trabalho de um grande número de mulheres pelo mercado. O desenvolvimento tardio da industrialização brasileira colocou essa exigência somente ao final do século XIX e primeiras décadas do XX, mas foi somente a partir da transformação da base econômica, com a efetivação do processo de industrialização que se deu, como é sabido, após 1930 e a grave crise econômica internacional e que, no país, significou a crise da economia agrárioexportadora-cafeeira.

Com o processo de industrialização foi se dando a incorporação das mulheres-mães ao mercado de trabalho, fator que, fundamentalmente, determinou a necessidade de criação de espaços institucionais destinados à criança de zero a seis anos. No Brasil, o surgimento e expansão das creches e pré-escolas marcaram a história do século XX e, inicialmente, foram instituídos como espaços de natureza assistencial, na maioria dos casos, sendo de atendimento de confessional e caritativo. Até muito recentemente, os preceitos religiosos e/ou higienistas marcaram as ações voltadas ao atendimento às crianças, numa estreita aliança entre as políticas públicas e concepções naturalizantes acerca do desenvolvimento humano.

A confusão entre políticas públicas e privadas no que diz respeito ao atendimento à criança prevaleceu (e ainda prevalece) no Brasil, tornando natural o trabalho assalariado da mulher e, por isso, a necessidade de cuidado com seus filhos. Não se colocou, em nenhum momento, em questão que se trata de um problema social que só existe por condições determinadas de classe e que levaram ao assalariamento não só do trabalhador, mas também de sua mulher e filhos. Certamente que esse não é um problema das classes e frações de classe abastadas e que, por sua condição de classe, tem como encaminhar doméstica ou institucionalmente os cuidados com seus filhos. A família trabalhadora não tem alternativas para equacionar os necessários cuidados e formação de seus filhos e, por isso, a institucionalização da creche no Brasil foi adquirindo feições assistencialistas, num primeiro momento, e na medida em que a regulamentação do trabalho foi se dando, também foi ocorrendo a necessidade de tornar obrigatório o cuidado com os filhos dos trabalhadores.

Certamente que com a CLT o direito a creche cobriu apenas o período de amamentação. Nem há muito o que discutir nessa direção, embora a letra da lei parece morta para parte do empresariado, bem como para vários dos sindicatos de trabalhadores. ENTRETANTO, o inciso XXV do art. $7^{\circ}$ da Constituição Federal, antes referido, tem certamente forte poder jurídico e ético, estabelecendo a assistência gratuita aos filhos dos trabalhadores do nascimento até os 5 anos de idade. Ainda que não haja referência direta, pelo conteúdo da Carta Magna parece não haver dúvidas de que aos patrões cabe essa obrigatoriedade e, por isso, nem há como deixar de reconhecer como direito líquido e certo a assistência e educação infantil para os filhos dos trabalhadores do nascimento até os 5 anos de idade (a partir de 2016 deverá ser estabelecido que é do nascimento até os 4 anos de idade).

Apesar do claro estabelecimento do direito à educação infantil e da obrigatoriedade da mesma ser de responsabilidade do empresariado, é certo que paira uma "névoa" sobre o assunto no exercício interpretativo da lei pelos juristas. Tanto é que já tramitou no 
Congresso Nacional um Projeto de Lei, de autoria do Senador Paulo Paim, buscando regulamentar a obrigatoriedade de atendimento gratuito, pelo patronato, em creches e préescolas, dos filhos dos trabalhadores urbanos e rurais. O projeto foi arquivado, aparentemente mantendo a cortina de fumaça sobre essa exigência legal.

Num processo de rápidas transformações conjunturais e estruturais de nossas formações sociais, com a marginalização crescente de amplos setores populacionais, com todas as consequências que isso implica, inclusive quanto a organização da família nuclear e extensa, seguindo os clássicos defensores da emancipação dos trabalhadores e de construção de uma sociedade igualitária, entendo que cabe ao Estado (em seus diversos níveis e instância) a formação das novas gerações, imbuídas de forte espírito crítico e de capacidade e competência para a luta transformadora. Para setores crescentes da população infantil as alternativas sociais vão se estreitando, e não é mera retórica afirmar que restam basicamente dois caminhos: a rua (e a marginalidade) ou a escola (e a opção por lutar pelas necessárias transformações sociais).

Mas este momento de transformação estrutural, apesar de já delinear a construção de um novo modo de produção da vida social, ainda é fortemente marcado pela transição e pelas formas mais características da barbárie econômica, social, política, jurídica, ética, etc. É preciso ampliar significativamente os recursos para a educação, para que o Estado possa dar conta de suas responsabilidades, nestes tempos de transição. Enquanto isso não ocorre e por isso mesmo, neste momento, não se pode eximir o empresariado de suas responsabilidades em financiar e atender a educação dos filhos de seus trabalhadores.

\section{Referências}

BRASIL. Constituição (1988). Constituição da República Federativa do Brasil. Brasília, DF : Senado, 1988

BRASIL. Consolidação das Leis do Trabalho. Decreto-lei no 5.452, de 1 de maio de 1943. Aprova a consolidação das leis do trabalho. Lex - Coletânea de Legislação: edição federal, São Paulo, v. 7, 1943.

IBGE. Censo 2010. Disponível em: <http://www.censo2010.ibge.gov.br/>. Acessado em: $10 /$ jan/2014

\section{Notas}

\footnotetext{
${ }^{1}$ Professor e pesquisador livre-docente do Departamento de Filosofia e História da Educação, da Faculdade de Educação da UNICAMP. Coordenador executivo do Grupo de Estudos e Pesquisas "História, Sociedade e Educação no Brasil” - HISTEDBR. Pesquisador do CNPq. Secretário da Educação de Limeira, SP.

${ }^{2}$ O IBGE disponibiliza essa informação através do seguinte endereço eletrônico: http://censo2010.ibge.gov.br/sinopse/webservice/frm_piramide.php Ou desde 1980 pelo site http://www.ibge.gov.br/home/estatistica/populacao/projecao_da_populacao/piramide/piramide.shtm ${ }^{3}$ A pirâmide populacional de Limeira, SP, pode ser acessada em http://www.censo2010.ibge.gov.br/sinopse/webservice/frm piramide.php?ano=2000\&codigo=352690\&corh omem $=3 \mathrm{~d} 4590 \&$ cormulher $=9 \mathrm{cdbfc} \&$ wmaxbarra $=180$
}

Recebido em fevereiro/14

Aprovado em março/14 